\title{
Sunny Upside? The Relationship Between Sunshine and Stock Market Returns
}

\author{
GARY SMITH \\ Pomona College* \\ MICHAEL ZURHELLEN \\ Pomona College
}

\begin{abstract}
Weather can have profound effects on economic activity, most obviously agriculture, construction, and transportation. It has also been reported that the daily weather in New York City affects U. S. stock returns, a clear challenge to the efficient market presumption that rational investors will not let their assessment of a stock's value be swayed by whether the sun happens to be shining. Studies claiming to have found a sunshine effect are clouded by differing methodologies which may have been chosen to buttress the results. We examine a fresh set of data and confirm the existence of a New York City sunshine effect which may have weakened over time as trading has become more geographically dispersed.
\end{abstract}

Keywords: weather and stock market, market efficiency

JEL Classifications: G14

\section{Introduction}

Several studies have found that people tend to be happier on sunny days and sadder on cloudy days. Lack of sunshine has been linked to increased depression (Eagles, 1994), as well as increased risk of suicide (Tietjen and Kripke, 1994). It has also been found that people suffering from bipolar depression have significantly shorter hospital stays when they are exposed to morning sunlight through an eastern facing window (Benedetti, et al, 2001).

Seasonal Affective Disorder (SAD) was first described by Rosenthal (1984), and has gained widespread acceptance after encountering early skepticism. SAD involves depression that sets in during the fall and winter months and subsides in the spring and summer, and is

\footnotetext{
* We are grateful for the helpful comments and suggestions from the REA's editors and referees and from Pomona College seminar participants Adam Belzberg, Aiden Buckley, Ishan Dutt, Angela Gunn, Mira Howard, Johnny Huynh, Alexander Johann, Julia Miller, and Kelly Ren.

(C) 2015; Gary Smith and Michael Zurhellen. Licensed under the Creative Commons Attribution Noncommercial 3.0 Licence (http://creativecommons.org/licenses/by-nc/3.0/. Available at http: //rofea.org.
} 
thought to be caused by reduced sunlight exposure which disrupts circadian rhythms as well as serotonin and melatonin levels (Mayo Clinic Staff, 2014). It is more prevalent farther from the equator, and is seldom found in countries within 30 degrees of the equator (WebMD, 2014). Recent research has shown that light therapy is as effective as antidepressants for the treatment of SAD (Westrin and Lam, 2007).

Some studies have also found that decisions can be affected by visceral factors like anger and pain (Loewenstein, 1996, 2000), and that judgments about risk rarely occur in an emotionally neutral setting (Johnson and Tversky, 1983). If so, perhaps investment decisions are influenced by sunlight.

Saunders (1993) investigated whether daily sunshine in New York City had a measurable effect on daily stock market returns, as gauged by percentage changes in the Dow Jones Industrial Average and the value-weighted and equal-weighted indexes compiled by the Center for Research in Security Prices (CSRP). Looking at New York City data from 1927 through 1989, with daily cloudiness at Central Park (1927-1960) and La Guardia Airport (1961-1989) recorded in whole numbers on a scale of 0 (completely cloudless all day) to 10 (completely cloudy all day), he found that the stock market did better on relatively sunny days than on completely cloudy days. He also observed a significant decrease in the strength of the correlation during the years 1983-1989, suggesting that the sunshine effect may have weakened over time.

Trombley (1997) argued that Saunders' conclusion depended on a peculiar comparison of days that were 0 percent to 20 percent cloudy with days that were 100 percent cloudy. Even more oddly, the reported relationship was due entirely to unusually high stock market returns on days that were 10 percent cloudy. Average daily stock returns on days with 0 percent clouds were the second lowest among the eleven cloud categories for the Dow and the CRSP value-weighted portfolios and in the middle of the pack for the CRSP equal-weighted portfolio.

Trombley also concluded that Saunders' sunshine effect only appeared in some subsets of the time period Saunders studied and, in particular, that there is no evidence of a sunshine effect before 1962, which does not support Saunders' theory that the effect has weakened over time.

These peculiarities suggest that the reported results may have been a small subset of many statistical tests that were conducted but not reported-which undermines the statistical significance of the results that were reported. As Nobel Laureate Ronald Coase (1988) wryly observed, "If you torture the data enough, nature will always confess." Kramer and Runde (1997) and Jacobsen and Marquering (2008) concluded that reported statistical relationships 


\section{SMITH, ZURHELLEN Sunshine and Stock Market Returns}

between the weather and stock returns may be a spurious correlations unearthed by data mining.

However, Hirshleifer and Shumway (2003) looked at twenty-six international stock exchanges using 1982-1997 International Surface Weather Conditions (ISWO) hourly observations of the total sky cover on a scale from 0 (clear) to 8 (overcast). They calculated the average sky cover each day during the hours 6 a.m. through 4 p.m. at locations near the 26 stock exchanges. They used these daily data to calculate the average sky cover during each week of the year at each location. Finally, they calculated the daily seasonally adjusted cloud cover SKC* by subtracting the historical weekly means from the daily observations.

They reported least squares estimates of the equation:

$$
r=\alpha+\beta S K C^{*}+\varepsilon
$$

where $r$ is the daily market return and SKC* is their seasonally adjusted measure of sky cover. Overall, they found cloudiness generally to be negatively correlated with daily stock returns, though the results were often not statistically significant at the 5 percent level. They also reported that their results were little affected by using sky cover data that were not seasonally adjusted.

Keef and Roush (2007) produced a meta-analysis of Hirshleifer and Shumway's results and added two new variables, latitude and per-capita GDP. They confirmed Hirshleifer and Shumway's overall findings, and also discovered that the strength of the sunshine effect grows with distance from the equator, with little or no effect at or near the equator. This similarity to SAD research strengthens the argument that mood changes are responsible for the relationship between sunshine and stock returns.

The primary inadequacy of the Hirshleifer/Shumway study is that they only considered a brief 16-year period, 1982-1997. We apply their approach to comparable New York City data for a longer time period, from 1948 through 2013, that incorporates 34 years before and 16 years after the period they studied. Our expectation was that their reported results may have been tainted by multiple tests and would not hold up when their procedure was applied to data that have not been contaminated by data dredging.

\section{Data}

The National Oceanic and Atmospheric Administration's National Climate Data Center (2014) has hourly LaGuardia sky-cover data for the years 1948 through 2013 using the same 0-to-8 scale as the Hirshleifer/Shumway data. Following Hirshleifer and Shumway, we

calculated the average cloudiness each day between the hours of 6 a.m. and 4 p.m. and 
adjusted these daily averages by subtracting each week's mean cloudiness (averaged over the whole period) from each daily average.

Hirshleifer and Shumway obtained daily stock returns from Datastream Global Index, but these data are only available back to 1973. So, we followed Saunders in using the Dow Jones Industrial Average and the CRSP value-weighted and equal-weighted indexes. Saunders used the daily percentage changes in each of these indexes, but we used CRSP returns that include dividends as well as price changes. We use daily percentage changes in the Dow because we do not have comparable daily returns including dividends.

\section{Results}

Table 1 shows the average stock returns on days that were perfectly sunny and on days that were completely cloudy every hour from 6 a.m. to 4 p.m. The full data set 1948-2013 was also broken into three subsets: the days before, during, and after the 1982-1997 years studied by Hirshleifer and Shumway. Overall, the average daily return was higher on cloudless days, with the magnitude of the difference and the statistical significance highest in the early years and diminishing over time.

Table 1 Daily Mean Returns on Perfectly Sunny $(C=0)$ and Completely Cloudy $(\mathrm{C}=8)$ Days

\begin{tabular}{|c|c|c|c|c|}
\hline & $1948-2013$ & $1948-1981$ & $1982-1997$ & $1998-2013$ \\
\hline \multicolumn{5}{|l|}{ Observations } \\
\hline $\mathrm{C}=0$ & 714 & 391 & 262 & 61 \\
\hline$C=8$ & 2645 & 1393 & 669 & 583 \\
\hline \multicolumn{5}{|l|}{ Dow } \\
\hline Mean, $C=0$ & 0.0547 & 0.0476 & 0.076 & 0.0068 \\
\hline Mean, $C=8$ & -0.0121 & -0.036 & -0.0194 & 0.0533 \\
\hline P-value & 0.0868 & 0.0328 & 0.2141 & 0.8133 \\
\hline \multicolumn{5}{|c|}{ CRSP value-weighted } \\
\hline Mean, $\mathrm{C}=0$ & 0.0733 & 0.0718 & 0.0906 & 0.0088 \\
\hline Mean, $C=8$ & 0.0082 & -0.0147 & -0.006 & 0.0791 \\
\hline P-value & 0.0767 & 0.0175 & 0.1545 & 0.7384 \\
\hline \multicolumn{5}{|c|}{ CRSP equal-weighted } \\
\hline Mean, $\mathrm{C}=0$ & 0.1018 & 0.1135 & 0.1136 & -0.0247 \\
\hline Mean, $C=8$ & 0.0379 & -0.0056 & 0.0661 & 0.1095 \\
\hline P-value & 0.0428 & 0.0005 & 0.3699 & 0.4614 \\
\hline
\end{tabular}


Notice that the return difference and the statistical significance generally increase as we move from the Dow Jones Industrial Average to the CRSP value-weighted index to the CRSP equal-weighted index, indicating that the sunshine effect is strongest for lightly capitalized stocks.

Table 2 is a similar analysis, this time comparing the ten percent of the days with the lowest seasonally adjusted cloud cover and the ten percent with the highest seasonally adjusted cloud cover. The differences between the average returns on the top-ten and bottomten cloudiness days are comparable to those for perfectly sunny versus completely cloudy days.

The differences in the average daily stock returns are substantial and statistically significant for the years 1948 through 1981, but diminish over time. Again the size of the differences and the statistical significance are more pronounced for relatively small stocks.

Table 2 Daily Mean Returns on the Ten Percent Sunniest (Low C) and Cloudiest (High C) Days

\begin{tabular}{|c|c|c|c|c|}
\hline & $1948-2013$ & 1948 - 1981 & $1982-1997$ & $1998-2013$ \\
\hline \multicolumn{5}{|l|}{ Observations } \\
\hline Low C & 1662 & 854 & 404 & 403 \\
\hline High C & 1690 & 874 & 404 & 404 \\
\hline \multicolumn{5}{|l|}{ Dow } \\
\hline Mean, Low C & 0.0575 & 0.0405 & 0.1449 & -0.0551 \\
\hline Mean, High C & 0.0313 & -0.0647 & -0.0262 & 0.0565 \\
\hline P-value & 0.0068 & 0.0035 & 0.161 & 0.9883 \\
\hline \multicolumn{5}{|c|}{ CRSP value-weighted } \\
\hline Mean, Low C & 0.0743 & 0.063 & 0.1513 & 0.085 \\
\hline Mean, High C & -0.0080 & -0.0249 & -0.0173 & 0.06 \\
\hline P-value & 0.0085 & 0.0107 & 0.007 & 0.7991 \\
\hline \multicolumn{5}{|c|}{ CRSP equal-weighted } \\
\hline Mean, Low C & 0.1054 & 0.1048 & 0.1621 & 0.1263 \\
\hline Mean, High C & 0.0024 & -0.0267 & 0.0175 & 0.0655 \\
\hline P-value & 0.0001 & 0.0001 & 0.0033 & 0.4701 \\
\hline
\end{tabular}


Review of Economic Analysis 7 (2015) 173-183

Table 3 GARCH Estimates of the Relationship Between Cloud Cover and Daily Stock Returns

\begin{tabular}{|l|r|r|r|r|r|}
\hline & $1948-2013$ & $1948-1981$ & $1982-1997$ & $1998-2013$ \\
\hline \hline Observations & 16,605 & 8,539 & 4,042 & 4,024 \\
\hline \hline Dow & 0.0315 & 0.0208 & 0.0597 & 0.0259 \\
\hline Mean Return & -0.0064 & -0.0058 & -0.0114 & -0.0042 \\
\hline Beta & 0.0023 & 0.0235 & 0.0142 & 0.4452 \\
\hline P-value & \multicolumn{5}{|l}{} \\
\hline CRSP value-weighted & 0.0457 & 0.0426 & 0.0643 & 0.0337 \\
\hline Mean Return & -0.0056 & -0.0044 & -0.0092 & -0.0057 \\
\hline Beta & 0.0041 & 0.0633 & 0.0184 & 0.3361 \\
\hline P-value & & & & \\
\hline CRSP equal-weighted & 0.0742 & 0.0636 & 0.0989 & 0.072 \\
\hline Mean Return & -0.0053 & -0.0049 & -0.0077 & -0.0051 \\
\hline Beta & 0.0023 & 0.025 & 0.0064 & 0.3169 \\
\hline P-value &
\end{tabular}

Table 3 shows the GARCH estimates with robust standard errors (Huber-White) of equation 1 using seasonally adjusted cloud cover data for the years 1948-2013 as a whole and broken into the years before, during, and after the Hirshleifer and Shumway study. We also estimated equation 1 using unadjusted data and found, as did Hirshleifer and Shumway, that the results were little affected.

With approximately 250 trading days a year, a -0.005 slope means that an extra degree of cloudiness reduces the annualized return by 1.25 percent. For all three measures of stock returns, there is a strong, statistically significant, inverse relationship between cloudiness and market returns for the period as a whole, but the relationship is not statistically significant at the 5 percent level after the 1982-1997 period studied by Hirshleifer and Shumway.

Hirshleifer and Shumway investigate a trading strategy based on the seasonally adjusted cloud cover each day between the hours of 5 a.m. and 8 a.m., before markets open. A morning was considered to have above-average cloudiness if the seasonally adjusted cloud cover was positive, and below-average cloudiness if the seasonally adjusted cloud cover was negative. It would be difficult to implement this strategy in practice because the weekly averages used to 


\section{SMITH, ZURHELLEN Sunshine and Stock Market Returns}

make the seasonal adjustments are not known until the end of the historical period being studied.

Instead, we investigated a trading strategy based on whether the sky was perfectly sunny or completely cloudy every hour between 5 a.m. and 8 a.m. The average returns were then compared for the days where the mornings were cloudless or entirely cloudy. (We didn't use the Dow data in these calculations because these only reflect price changes, not total returns including dividends.)

Table 4 shows that the average returns were consistently higher on days that began perfectly sunny compared to days that began completely cloudy. The differences are most pronounced for the equal-weighted index and are more statistically significant for the years 1948-1981 than for later years. Interestingly, the differences in returns are largest for the years 1998-2013, after the Hirshleifer/Shumway study, though not statistically significant at the 5 percent level.

Table 4 Comparison of Daily Mean Returns From Strategy Based on Days That Were Perfectly Sunny $(C=0)$ and Completely Cloudy $(C=8)$ Days

Between 5 a.m. and 8 a.m

\begin{tabular}{|c|c|c|c|c|}
\hline & $1948-2013$ & $1948-1981$ & 1982 - 1997 & $1998-2013$ \\
\hline \multicolumn{5}{|l|}{ Observations } \\
\hline $\mathrm{C}=0$ & 3686 & 2030 & 913 & 743 \\
\hline$C=8$ & 4691 & 2480 & 1095 & 1116 \\
\hline \multicolumn{5}{|c|}{ CRSP value-weighted } \\
\hline Mean, $\mathrm{C}=0$ & 0.0602 & 0.0505 & 0.0748 & 0.0684 \\
\hline Mean, $C=8$ & 0.0228 & 0.0233 & 0.0355 & 0.0091 \\
\hline P-value & 0.0671 & 0.2084 & 0.3555 & 0.3262 \\
\hline \multicolumn{5}{|c|}{ CRSP equal-weighted } \\
\hline Mean, $C=0$ & 0.0896 & 0.0809 & 0.0914 & 0.1111 \\
\hline Mean, $C=8$ & 0.0505 & 0.0363 & 0.0845 & 0.0489 \\
\hline P-value & 0.0266 & 0.0339 & 0.8217 & 0.2272 \\
\hline
\end{tabular}


We also calculated the daily returns from the following trading strategy. Invest in Treasury bills until a day when it is perfectly sunny between 5:00 a.m. and 8:00 a.m.; then invest in stocks fully when the stock markets open and remain fully invested until a day when it is completely cloudy between 5:00 a.m. and 8:00 a.m.; then liquidate stocks when the market opens and invest in Treasury bills, and so on.

We gauged the success of this strategy by estimating the Fama-French (1993) three-factor model using daily data from French (2016).

$$
R=\alpha+\beta_{1} M K T+\beta_{2} S M B+\beta_{3} H M L+\beta_{4} U M D+\varepsilon
$$

where

$$
\begin{aligned}
& R=\text { return on trading portfolio minus the return on Treasury bills } \\
& M K T=\text { value-weighted return on all NYSE, AMEX, and NASDAQ stocks (from } \\
& \text { CRSP) minus the return on Treasury bills } \\
& S M B=\text { average return on three small-stock portfolios minus the average return on } \\
& \text { three large-stock portfolios (size factor) } \\
& H M L=\text { average return on two value portfolios minus the average return on two } \\
& \text { growth portfolios (value factor) }
\end{aligned}
$$

The Fama-French model embodies the historical evidence that: (a) common macro factors affect stock returns; (b) small stocks tend to do relatively well (Banz, 1981; Reinganum, 1981); and (c) value stocks tend to do relatively well (Rosenberg, Reid and Lanstein, 1985).

Table 5 shows the estimates for the period as a whole and for the three subperiods. For the equal-weighted portfolios, all of the estimated coefficients of Fama-French factors are positive and highly statistically significant. The results are less consistent for the valueweighted portfolios.

The betas for the market factor are generally less than 0.5 for both portfolios because the trading strategy is often invested in Treasury bills. The equal-weighted portfolios do much better than value-weighted portfolios when small stocks are doing well relative to large stocks and somewhat better when value stocks are doing well relative to growth stocks.

The alphas are not statistically significant at the 5-percent level for the value-weighted portfolios, but are significant for all time periods other than 1982-1987 for the equal-weighted portfolios. A daily alpha of 0.01 is an annualized excess return of 2.5 percent. Consistent with Table 4, the alphas are largest for the years 1998-2013, after the Hirshleifer/Shumway study. 
SMITH, ZURHELLEN Sunshine and Stock Market Returns

Table 5 Estimates of the Fama-French Three-Factor Model

\begin{tabular}{|c|c|c|c|c|c|c|c|c|}
\hline & \multicolumn{2}{|c|}{$1948-2013$} & \multicolumn{2}{|c|}{$1948-1981$} & \multicolumn{2}{|c|}{ 1982-1997 } & \multicolumn{2}{|c|}{$1998-2013$} \\
\hline \multicolumn{9}{|c|}{ CRSP value-weighted } \\
\hline Intercept & 0.004 & [1.096] & 0.001 & [0.321] & -0.007 & [0.669] & 0.012 & {$[1.295]$} \\
\hline MKT & 0.442 & [17.66] & 0.481 & [24.53] & 0.553 & [7.434] & 0.39 & [12.17] \\
\hline SMB & -0.020 & [1.028] & $\begin{array}{r}- \\
0.039\end{array}$ & [-1.825] & 0.034 & [1.273] & 0.028 & [1.001] \\
\hline HML & -0.020 & {$[0.753]$} & 0.004 & [0.165] & 0.107 & [1.407] & -0.024 & {$[0.527]$} \\
\hline $\mathrm{R}^{2}$ & 0.45 & & 0.48 & & 0.52 & & 0.4 & \\
\hline \multicolumn{9}{|c|}{ CRSP equal-weighted } \\
\hline Intercept & 0.015 & [4.015] & 0.009 & [2.128] & 0.008 & [0.941] & 0.027 & {$[2.765]$} \\
\hline MKT & 0.362 & [17.78] & 0.441 & [23.29] & 0.469 & [7.311] & 0.297 & [12.04] \\
\hline SMB & 0.279 & [13.38] & 0.329 & [11.94] & 0.431 & [6.379] & 0.236 & [9.981] \\
\hline HML & 0.081 & [3.166] & 0.12 & [4.62] & 0.12 & [2.333] & 0.089 & [2.612] \\
\hline $\mathrm{R}^{2}$ & 0.41 & & 0.45 & & 0.51 & & 0.38 & \\
\hline
\end{tabular}

Note: Robust (absolute) t-values in parantheses

\section{Conclusions}

To our surprise, our study confirms that the U.S. stock market has done better on sunny days than on cloudy days even though daily fluctuations in New York's cloudiness do not affect the fundamental value of the stocks being traded. We also find that the sunshine effect is strongest for lightly capitalized stocks.

Robert Shiller (1984), among others, has argued that the empirical observation that it is difficult to beat the stock market does not prove that stock prices are "correct" in the sense that they are equal to an objective present value calculation of the best estimates of future cash flows. It is also difficult to predict stock prices that are buffeted by fads, fancies, greed, and gloom—what Keynes called "animal spirits. Our findings are consistent with the view that stock prices can be swayed by something as meaningless as whether the sun is shining. 


\section{References}

Amador, M., Werning, I., and Angeletos, G-M. (2006). Commitment vs. Flexibility. Econometrica, 74(2), 365-396.

Banz, R. (1981). The relationship between return and market value of common stocks. Journal of Financial Economics, 9(1), 3-18.

Coase, R. (1988). How should economists choose?, in Ideas, Their Origins and Their Consequences: Lectures to Commemorate the Life and Work of G. Warren Nutter, American Enterprise Institute for Public Policy Research.

Benedetti, F., Colombo, C., Barbini, B., Campori, E., and Smeraldi, E. (2001). Morning sunlight reduces length of hospitalization in bipolar depression. Journal of Affective Disorders, 62(3), 221-223.

Eagles, J. (1994). The relationship between mood and daily hours of sunlight in rapid cycling bipolar illness. Biological Psychiatry, 36(6), 422-424.

Fama, E.F., French, K.R. (1993). Common risk factors in the returns on bonds and stocks. Journal of Financial Economics, 33 (1), 3-56.

French, K.R., (2016). Data Library. Available at http://mba.tuck.dartmouth.edu/pages/faculty/ken.french/data_library.html.

Hirshleifer, D., Shumway, T. (2003). Good day sunshine: Stock returns and the weather. Journal of Finance, 58(3), 1009-1032.

Jacobsen, B., Marquering, W. (2008). Is it the weather? Journal of Banking and Finance, 32(4), 526-540.

Johnson, E., Tversky, A., (1983). Affect, generalization, and the perception of risk. Journal of Personality and Social Psychology, 45(1), 20-31.

Keef, S., Roush, M. (2007). A meta-analysis of the international evidence of cloud cover on stock returns. Review of Accounting and Finance, 6(3), 324-338.

Kramer, W., Runde, R., (1997). Stocks and the weather: An exercise in data mining or yet another capital market anomaly? Empirical Economics, 22(4), 637-641.

Loewenstein, G. (1996). Out of control: Visceral influences on behavior. Organizational Behavior and Human Decision Processes, 65(3), 272-292.

Loewenstein, G. (2000). Emotions in economic theory and economic behavior. American Economic Review, 90(2), 426-432.

Mayo Clinic Staff (2014), Seasonal Affective Disorder (SAD): Causes. Available at http://www.mayoclinic.org/diseases-conditions/seasonal-affectivedisorder/basics/causes/CON-20021047.

National Climate Data Center, NOAA (2014). Available at http://www.ncdc.noaa.gov.

Reinganum, M. (1981). Misspecification of capital asset pricing: Empirical anomalies based on earnings' yields and market values. Journal of Financial Economics, 9(1), 19-46. 


\section{SMITH, ZURHELLEN Sunshine and Stock Market Returns}

Rosenberg, B., Reid, K., and Lanstein, R. (1985). Persuasive evidence of market inefficiency. Journal of Portfolio Management, 11, 9-17.

Rosenthal, N. (1984). Seasonal affective disorder: A description of the syndrome and preliminary findings with light therapy. Archives of General Psychiatry, 41(1), 72-80.

Saunders, E., Jr. (1993). Stock prices and Wall Street weather. American Economic Review, 83(5), 1337-1345.

WebMD (2014). Seasonal depression (seasonal affective disorder). Available at http://www.webmd.com/depression/guide/seasonal-affective-disorder.

Shiller, R. (1984). Stock prices and social dynamics. Brookings Papers on Economic Activity, 1984(2), 457-498.

Tietjen, G., Kripke, D. (1994). Suicides in California 1968-1977: Absence of seasonality in Los Angeles and Sacramento counties. Psychiatric Research, 53(2), 161-172.

Trombley, M. (1997). Stock prices and Wall Street weather: Additional evidence. Quarterly Journal of Business and Economics, 36(3), 11-21. 